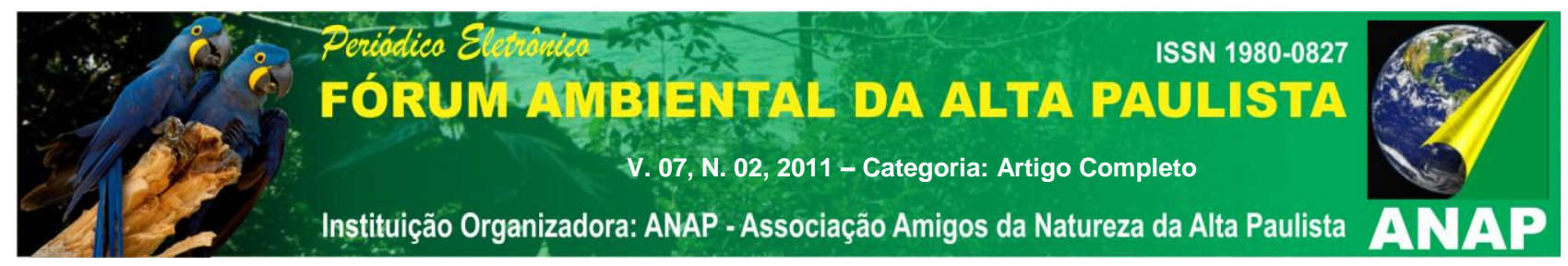

\title{
GEOTECNOLOGIAS APLICADAS NA ANÁLISE MULTITEMPORAL NO SUBSISTEMA BACIA HIDROGRÁFICA DO CÓRREGO DOM TOMAZ NO MUNICÍPIO DE TRÊS LAGOAS/MS (1985 Á 2011).
}

\author{
Flávia Joise Izippato ${ }^{1}$ \\ Eduardo Vinicius Rocha Pire ${ }^{2}$ \\ Renan de Almeida Silva ${ }^{3}$ \\ Patrícia Helena Mirandola ${ }^{4}$
}

\begin{abstract}
RESUMO: $O$ trabalho tem por objetivo desenvolver uma análise do ambiente, onde esta inserida a bacia hidrográfica do córrego Dom Tomaz (BHCDT), localizada no município de Três Lagoas/MS, a partir das geotecnologias disponíveis (sensoriamento remoto, GPS, cartografia automatizada, SIG [Sistema de Informação geográfico] e geoprocessamento). Destacando que estas permitem atualmente retratar o ambiente natural e/ou alterado, devido às ações antrópicas, de forma bem próxima da realidade encontrada no campo. Neste estudo foi possível identificar tais alterações que ocorreram nas áreas do entorno da bacia hidrográfica. Foram mapeadas e quantificadas a partir do processamento digital de imagem Landsat 5 sensor TM de 1985/07/30 e 2011/06/20, o uso e cobertura da terra. Na área o uso é intenso pela pecuária, atrelada a perda efetiva de vegetações naturais florestais e campestres (campos limpo e sujo), observa-se também a produção de silvicultura (eucalipto), mais intensificada no ano de 2011, devido à instalação da indústria Fibria. É passível de identificação a falta de cobertura vegetal natural nas margens e nascentes, que estão sendo utilizadas por atividades atreladas a atividade econômicas.
\end{abstract}

Palavras-chave: Geotecnologias. Bacia-Hidrográfica. Teoria Geral do Sistema.

\footnotetext{
${ }^{1}$ Mestranda do Programa de Pós-graduação em geografia UFMS/CPTL. Bolsista Capes e membro do DIGEAGEO (Diretrizes de Gestão Ambiental com Uso de Geotecnologias). Email: flaviajoise@gmail.com ${ }^{2}$ Graduando em geografia - UFMS/CPTL. Bolsista de iniciação científica PIBIC - CNPq e membro do DIGEAGEO (Diretrizes de Gestão Ambiental com Uso de Geotecnologias). Email: drocha.geo@gmail.com

${ }^{3}$ Graduando em geografia - UFMS/CPTL. Bolsista de iniciação científica PIBIC - CNPq e membro do DIGEAGEO (Diretrizes de Gestão Ambiental com Uso de Geotecnologias). Email: geo.renanalmeida@gmail.com

${ }^{4}$ Docente do Programa de Pós-graduação em geografia - UFMS/CPTL. Líder do grupo DIGEAGEO (Diretrizes de Gestão Ambiental com Uso de Geotecnologias). Email: patriciaufmsgeografia@gmail.com
} 


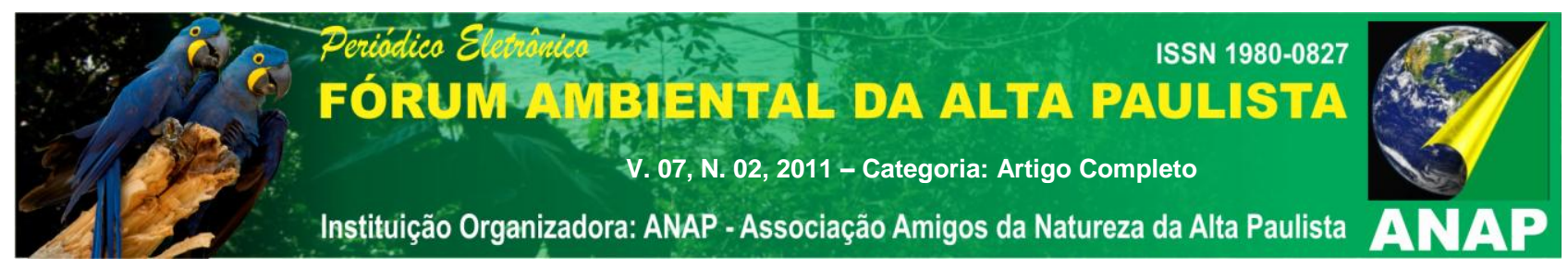

\section{INTRODUÇÃO}

As alterações ambientais são processos que ocorrem sempre que a ação antrópica se desenvolve de forma intensa em uma determinada área. A intensidade destas alterações pode determinar, no entanto a ocorrência de impactos no meio ambiente. Em áreas rurais estas se intensificam muito em áreas próximas aos corpos d'água, devido à falta de técnicas de manejo para o uso da terra principalmente pelas atividades que envolvem a pecuária.

Sendo assim são as bacias hidrográficas um dos principais referenciais de processos de alterações aceleradas no ambiente. Esta atualmente é considerada a principal ferramenta de análise e aplicação de medidas para o planejamento em áreas degradadas. Esta pode ser considerada um grande sistema ambiental aberto, onde podemos verificar constantes trocas de energia e matéria.

Christofoletti (1999) ressalta que os sistemas abertos são aqueles onde se verifica intensa troca de energia e matéria, (fluxo de entrada e saída). Dentre os sistemas abertos o mais comum, e bem exemplificado são as bacias hidrográficas.

Segundo Tricart:

O conceito de sistema é, atualmente, o melhor instrumento lógico de que dispomos para estudar os problemas do meio ambiente. Ele permite adotar uma atitude dialética entre a necessidade da análise - que resulta do próprio progresso da ciência e das técnicas de investigação - e a necessidade, contrária, de uma visão de conjunto, capaz de ensejar uma atuação eficaz sobre esse meio ambiente. Ainda mais, o conceito de sistema é, por natureza, de caráter dinâmico e por isso adequado a fornecer os conhecimentos básicos para uma atuação - o que não é o caso de um inventário, por natureza estático (TRICART, 1977, p.19).

Considerando o ambiente um sistema ambiental e analisando sobre esta perspectiva Bertalanffy (1972), propõe um estudo deste a partir da Teoria Geral do Sistema. Neste são considerados as partes que compõe o sistema a ser analisado, sendo o estudo dirigido para uma análise onde são considerado as partes, para que seja possível analisar o todo, "sistema", sempre de forma holística e integrada entre si. Este é então compreendido como sistema, subsistema e parte componente. 


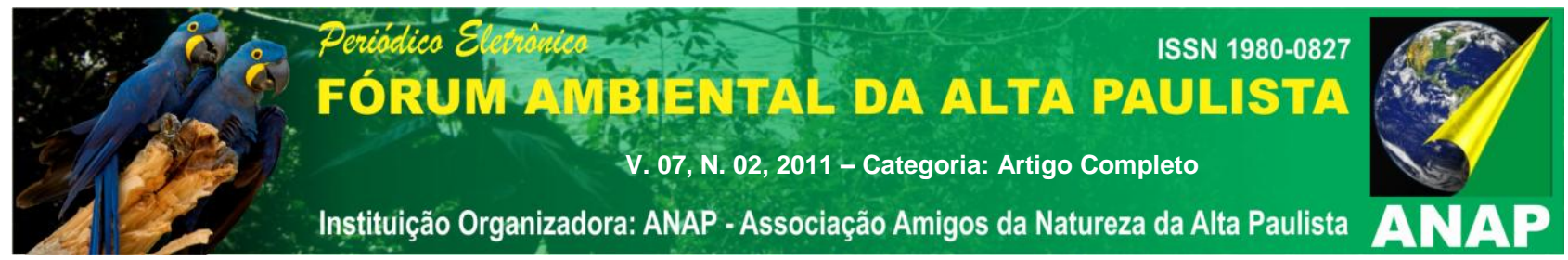

É necessário estudar não somente partes e processos isoladamente, mas também resolver os decisivos problemas encontrados na organização e na ordem que os unifica, resultante da interação dinâmica das partes, tornando o comportamento das partes diferente quando estudado isoladamente e quando tratado no todo (BERTALANFFY, 1972, p. 53)

Com isso tem-se destaque o papel a ser desenvolvido pelas ciências que utilizam as tecnologias na análise deste sistema alterado pelo homem. Estas permitem uma análise rápida e eficiente a partir do uso das geotecnologias disponíveis. Dentre estas estão inseridas 0 uso de sensores remotos, GPS, cartografia automatizada, geoprocessamento e SIG (Sistema de Informação Geográfico), que possibilita recriar o ambiente da forma mais próxima da realidade possível, dependendo sempre da alta capacidade de interpretação dos dados destes sensores (fotointerpretação).

Segundo Araujo; Almeida \& Guerra (2008) as pesquisas desenvolvidas antes destas tecnologias eram realizadas apenas em níveis dos ambientes das fazendas, mas atualmente com o uso destas é possível retratar o ambiente de forma mais integrada e real, impossível de ser visto anteriormente.

Vale destacar então a importância do geoprocessamento na manipulação destas tecnologias, já que informações tratadas dentro do ambiente geotecnológico fazem parte do conjunto de tarefas desenvolvidas pelo geoprocessamento.

Davis \& Câmara (2008), destaca que o geoprocessamento faz uso de um conjunto de tecnologias para coleta e tratamento espacial. Ele permite que através destes dados analistas possam determinar a evolução tempo-espaço, de fenômenos geográficos e suas relações.

Segundo Mirandola (2006) o geoprocessamento configura o conhecimento e manipulação de dados através de cartografia digital, sensores remotos, estatísticas e SIG.

Os sensores remotos são os responsáveis e permitem adquirir informações de um alvo estabelecido a partir de longas distancias. Novo (1989) discorre que o Sensoriamento Remoto é a capacidade de captar dados de um alvo e/ou objeto sem a necessidade de contato direto com o mesmo.

Os sensores remotos fazem uso de dispositivos capazes de captar a energia refletida ou emitida pela superfície, e registrá-la a partir de dados digitais (imagens, gráficas, dados numéricos etc.) Fitz (2008). 


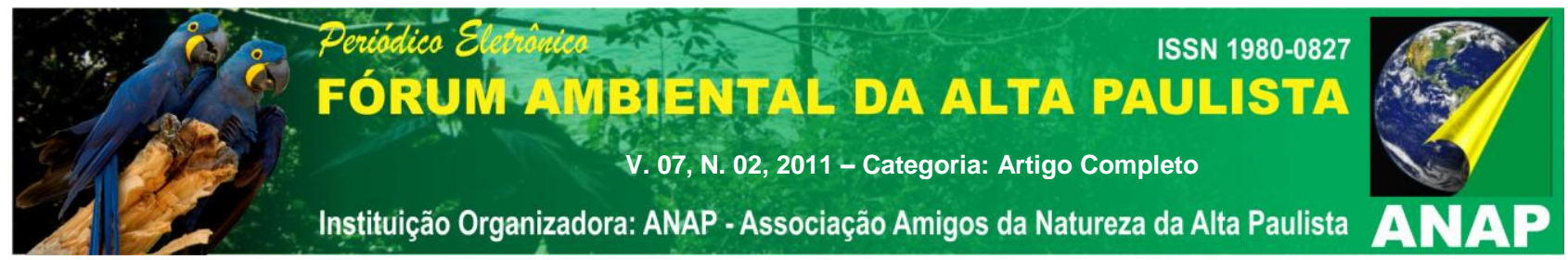

E o Sistema de Informação Geográfico (SIG) permite a manipulação, tratamento e armazenamento destes dados e de uma gama enorme de informações em um banco de dados georreferenciados, a partir de um conjunto de coordenadas $x, y$.

O SIG realiza tratamento computacional de dados geográficos e recupera informações não apenas com base em suas características alfanuméricas, mas também através de sua localização espacial (DAVIS \& CÂMARA, 2001, p.1).

São sistemas complexos (hardware, software, dados e informações) que necessita de pessoal habilitado para realizar análise do ambiente. As aplicações são diferenciadas, indo desde análise através de banco de dados espacial, cadastral, modelo numérico do terreno, redes (PARANHOS FILHO; LASTORIA \& TORRES, 2008).

Atualmente existem diferentes SIGs disponíveis no mercado, o Spring® 5.0.6 é um destes softwares. Foi desenvolvido pelo Instituto Nacional de Pesquisas Espaciais (INPE), sendo seu uso gratuito. Os documentos confeccionados por este software são eficientes, e representa a superfície terrestre de forma satisfatória.

\subsection{LOCALIZAÇÃO DA ÁREA DE ESTUDO}

O Córrego Dom Tomaz está a sudeste do município de Três Lagoas/MS, porção leste do Estado de Mato Grosso Sul. Ocupa uma área de aproximadamente 122,6 km², obtidos a partir da imagem Landsat 5 sensor TM no software Spring® 5.0.6. (Figura 01).

Segundo Seplan (1990), esta localizada na bacia sedimentar do Paraná, que geologicamente é composta por depósitos do grupo Bauru, constituído por rochas das Formações Santo Anastácio, Adamantina e Marília, com predominância da Formação Santo Anastácio (Ksa). O solo predominante é o Latossolo Vermelho-Escuro. A vegetação original ou remanescente desta região é savana (cerrado).

Segundo Köpen o clima característico é o denominado Aw (savanas), apresentando inverno seco e chuvas máximas de verão. A precipitação pluviométrica anual varia entre 1750 a 2000 mm anuais, excedente hídrico anual de 1200 a 1400 mm durante 07 a 08 meses e deficiência hídrica de 200 a 350 mm durante 03 meses. (SEPLAN, 1990). 


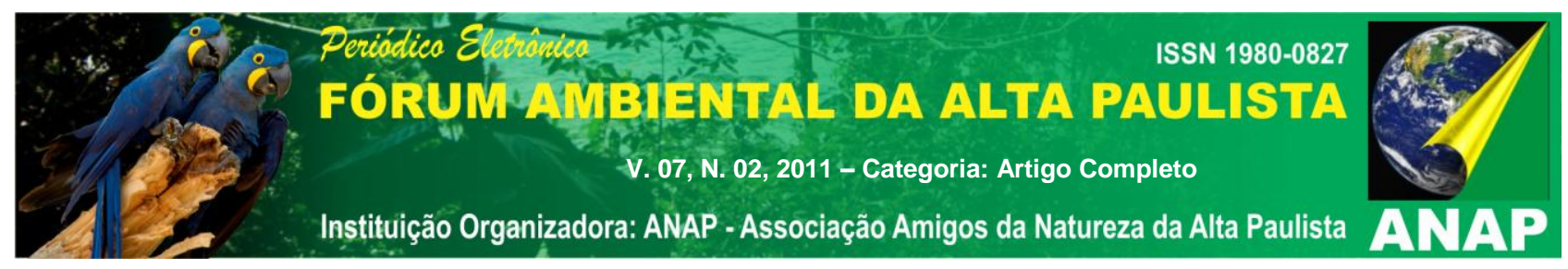

A partir então de uma análise ambiental considerado os sistemas ambientais abertos (BHCDT), e análise a partir da Teoria Geral do Sistema podemos hierarquizar a área de estudo da seguinte forma:

- Sistema: BH. do Rio Paraná (BHRP).

- Subsistema: BH. do Rio Sucuriú (BHRS).

- Parte componente: BH. do Córrego Dom Tomaz (BHCDT). 

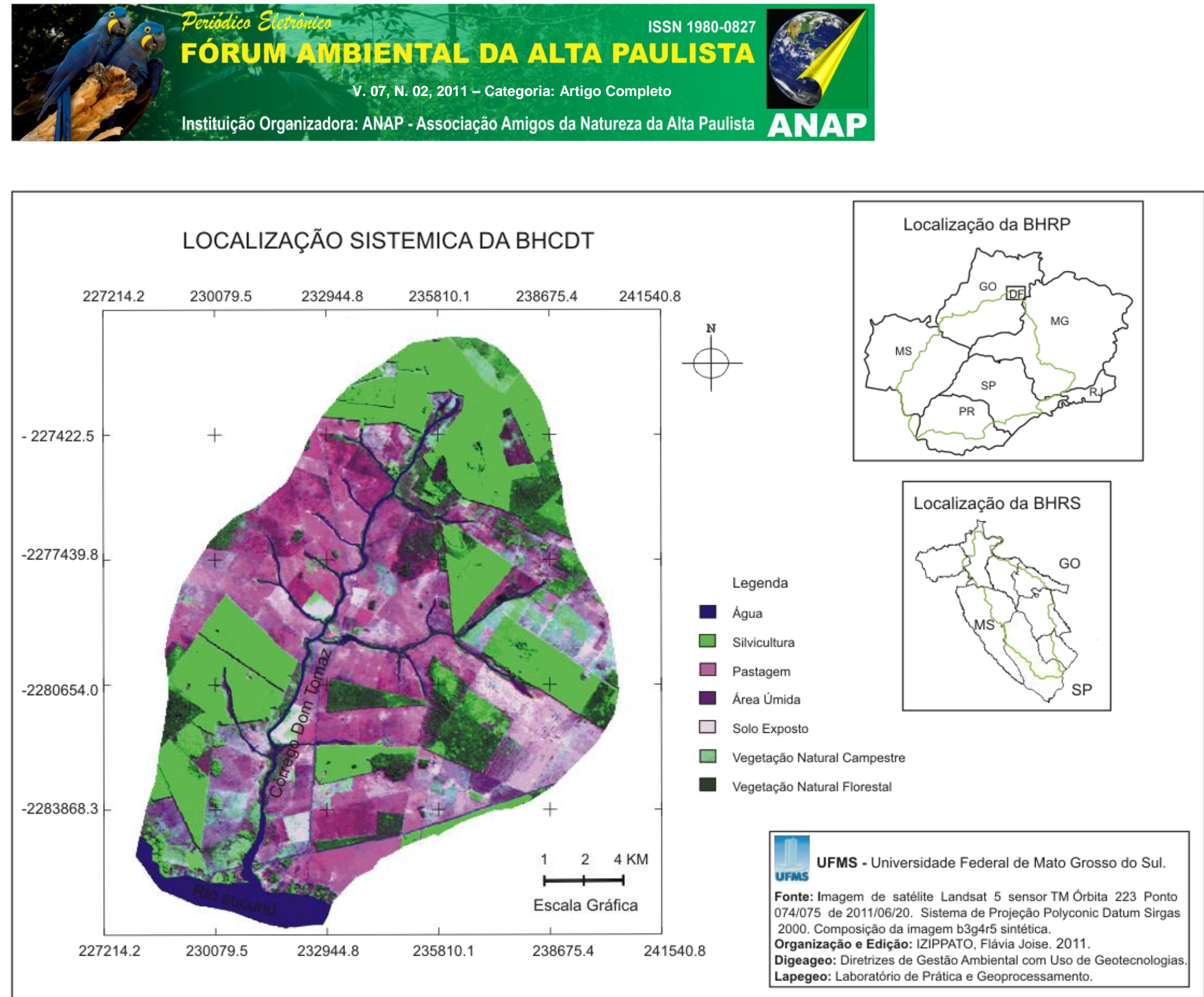


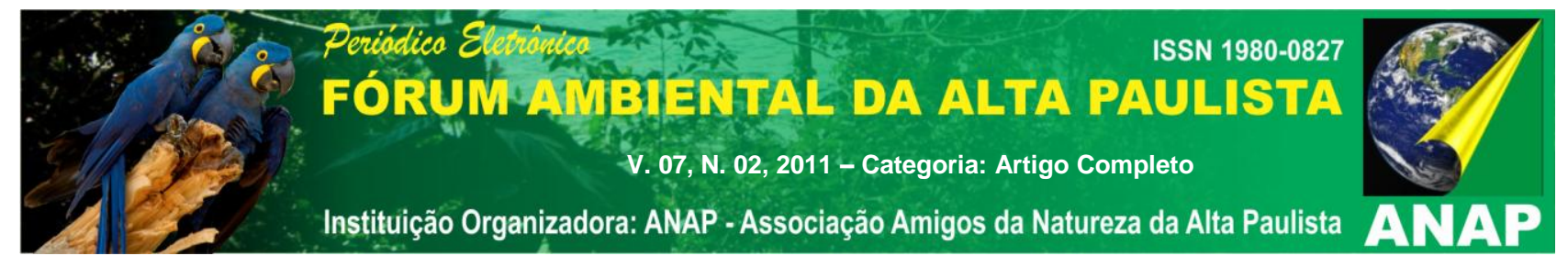

Figura 01: Mapa de Localização da Bacia Hidrográfica Córrego Dom Tomaz. 


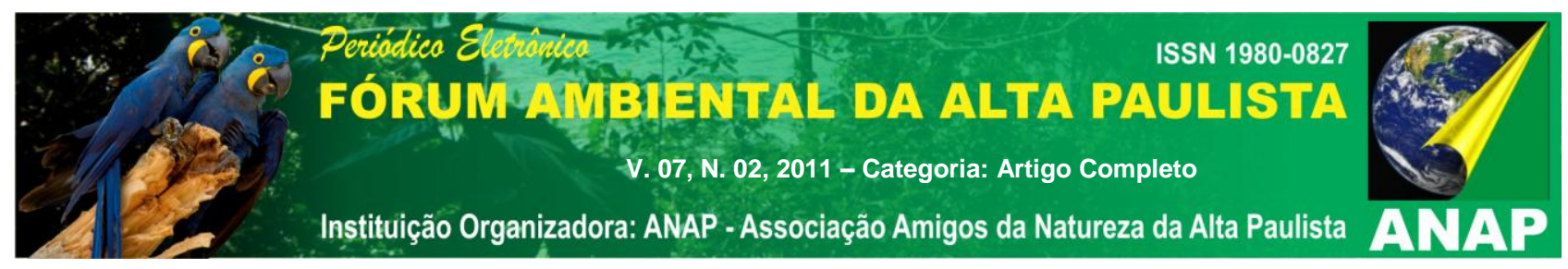

\section{METODOLOGIA DE PESQUISA}

2.1 Metodologia de Processamento Digital de Imagem (dpi) Landsat (land remote sensing satélite) 5 sensor TM (thematic mapper) no Software Spring® 5.0.6.

Após aquisição das imagens no formato TIFF no site do INPE, estas são convertidas para o formato compatível no Spring® 5.0.6 no módulo Impima 5.0.6, extensão do software Spring ${ }^{\circledR}$ 5.0.6, e tem como função, converter as imagens adquiridas para manipulação no software. A conversão da Imagem TIFF é efetuada no Impima 5.0.6, a manipulação o processamento e tratamento no software Spring® ${ }^{\circledR} .0 .6$ e finalização no módulo Scarta 5.0.6, extensão do Spring® 5.0.6, responsável pela finalização (layout) do mapeamento (mapa).

O tratamento das imagens no software Spring® 5.0.6 será efetuado após a criação do projeto no banco de dados disponível no site www.inpe.br, obtido após download do mesmo. O projeto é criado no banco de dados Atlas_2008 no qual são obtidas informações compatíveis com o projeto desenvolvido (Dom_Tomaz), a partir do projeto Sirgas_2000.

Após criar projeto à próxima etapa será o georreferenciamento da mesma a partir de pontos de controle passíveis de identificação na imagem, o Spring® é um SIG (Sistema de Informação Geográfico), que realiza suas funções a partir de dados referenciados em um sistema de coordenadas $x$ e y. A próxima etapa será o de importalás para o Spring ${ }^{\circledR}$ 5.0.6, para o tratamento.

Para importar as imagens é necessário escolher as bandas no qual será realizado o tratamento no software. Sendo assim é importante conhecer as funções de imageamento espectral de cada banda do satélite no qual se esta trabalhando (Landsat 5 sensor TM) e escolher as bandas no qual se terá a melhor "assinatura espectral", representação da superfície terrestre, da área escolhida. Segundo Paranhos Filho et al (2008), os tipos de cobertura no solo, absorve porções específicas do espectro eletromagnético, o que diferencia as respostas espectrais, resultando em uma "assinatura espectral" para cada tipo de cobertura do solo 


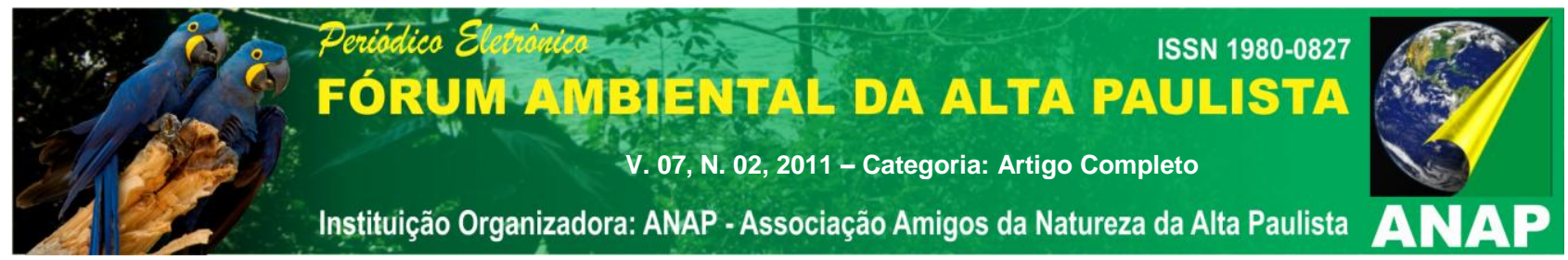

No satélite Landsat 5 sensor TM o número de bandas somam um total de 7 . Sendo definido importar as bandas 3, 4 e 5, para tratamento no software, pois estas permitem uma boa identificação de espécies de vegetações e manchas urbanas (banda 3), limites de corpos de água, drenagens e áreas agrícolas (banda 4) e umidade do solo e vegetação (banda 5).

Após importar as imagens (bandas) o contraste foi executado a fim de melhorar a qualidade, utilizando-se a opção Equalizar Histograma. A partir desse contraste, é feita a composição colorida, salva como imagem sintética b3g4r5, a qual possibilitará a classificação do uso e cobertura da terra na área de estudo. O recorte da área do Córrego foi executado em ferramenta recorte de plano de informação utilizando a imagem da missão SRTM.

A classificação foi por segmentação, onde foi dividida a área por regiões, que corresponde aos números de pixels que a imagem apresenta e sua similaridade. Foi utilizado o método de crescimento de regiões, com similaridade 8 e área (pixel) 10, após a segmentação foi utilizado o classificador Bhattacharya com limiar de aceitação de 99,9\%.

Este classificador: "[...] mede a distância média entre as distribuições de probabilidades de classes espectrais. O princípio é análogo ao utilizado para o classificador Isoseg, porém a medida de distância usada é a distancia de Battacharya". (Spring® 5.0.6). O classificador Battacharya, ao contrário do Isoseg que é automático, requer interação do usuário, através do treinamento. Neste caso, as amostras serão as regiões formadas na segmentação de imagens (Spring® 5.0.6).

Após a classificação, o mapeamento de classes do uso e cobertura da terra foi executado. Para os dados referentes à caracterização da área foram definidas 7 classes, sendo estas: vegetação natural florestal, vegetação natural campestre, área úmida, silvicultura, pastagem e água, de acordo com a proposta do Manual do Uso da Terra elaborado pelo IBGE (Instituto Brasileiro de Geografia e Estatística) em 2006, ressaltando que este sofreu adaptação devido à caracterização de áreas úmidas e solos expostos, estas passível de ser identificado na imagem em laboratório. Figura 02 etapas de PDI. 

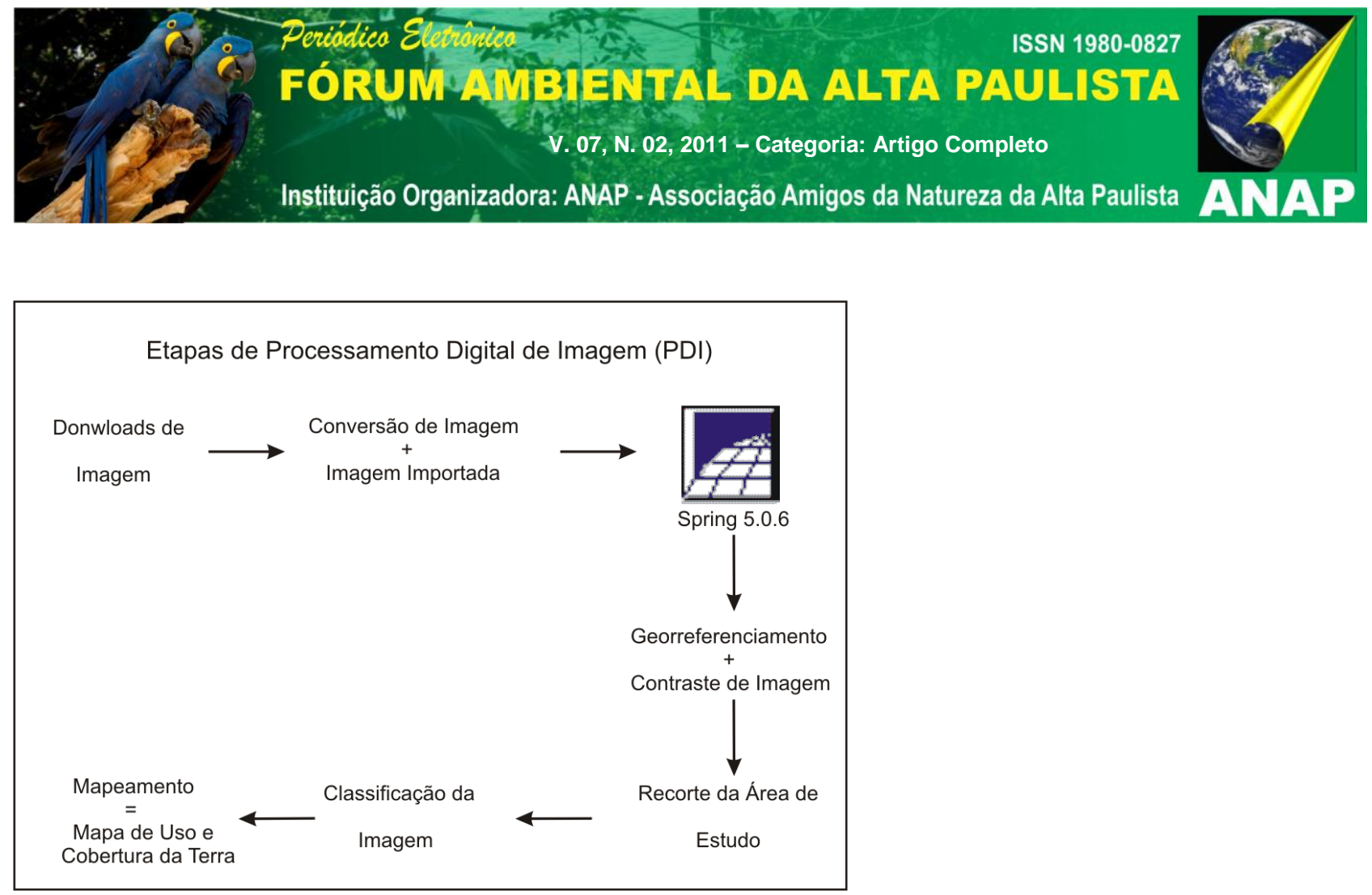

Figura 02: Etapas de Processamento Digital de Imagem de satélite.

\section{DESENVOLVIMENTO}

Após processamento digital da imagem Landsat 5 sensor TM de 1985/07/30 e 2011/06/20, no software Spring® 5.0.6, foram mapeadas 7 classes de uso e cobertura da terra, como estabelece o Manual do Uso da Terra (IBGE, 2006) sendo estas: Vegetação Natural Florestal, Vegetação Natural Campestre, Áreas Úmidas, Solo Exposto, Silvicultura, Pastagem e Água. A seguir o Gráfico 01 apresenta os valores percentuais aproximados do uso e cobertura da terra ao longo de 26 anos no Córrego Dom Tomaz.

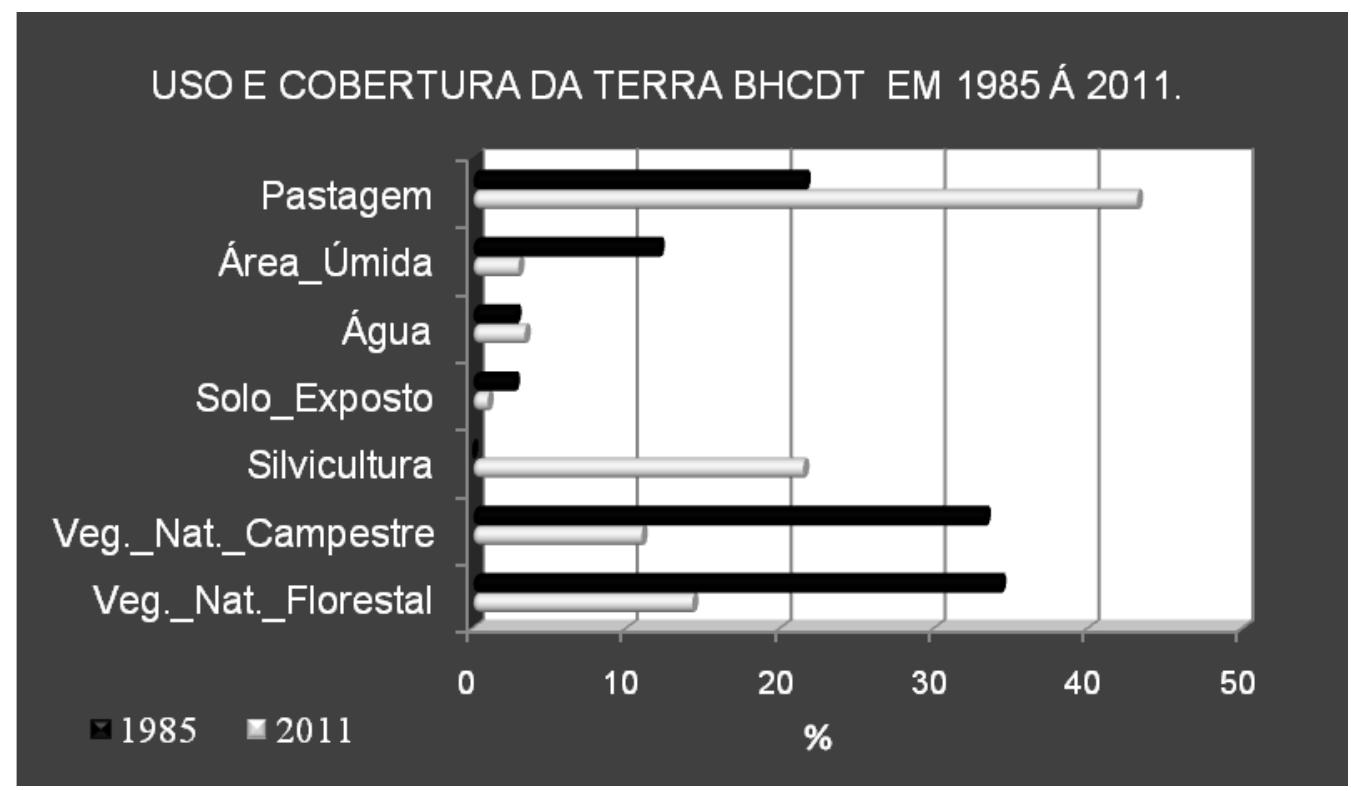

Gráfico 01: Comparativo Uso e Cobertura da Terra no Córrego Dom Tomaz em 1985/2011. 


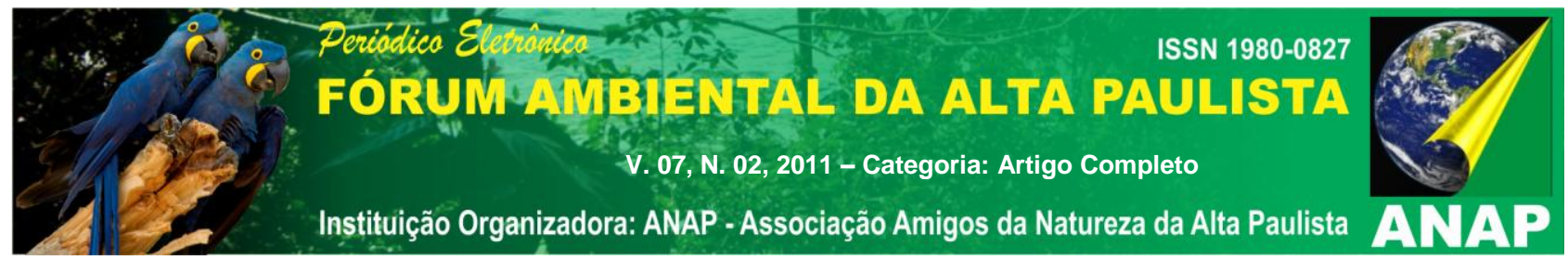

Fonte: Processamento Digital de imagem de satélite Landsat 5 sensor TM 1985/07/30 e 2011/06/20.

Organização: IZIPPATO, Flávia Joise. 2011.

Os resultados apresentados apontaram um progressivo processo de antropização na área do entorno do Córrego Dom Tomaz. Como pode ser observada, a vegetação natural florestal, sofreu uma redução total de cerca de 20\%. Em 1985 ocupava aproximadamente $34.3 \%$ e no ano de 2011 recobre 14.3\%. Esta redução de vegetação ocorre também com a vegetação natural campestre (campo limpo e sujo). Que juntamente com a vegetação natural florestal campestre era a principal paisagem. Em 1985 esta vegetação ocupava 33.3\% e em 2011 sofre uma redução ainda maior se comparado com a vegetação natural florestal, atingindo $11 \%$. Neste caso a perda deste tipo de vegetação atinge $22 \%$ do total da área.

Se forem somadas as perdas destas vegetações estas atingem $42 \%$ do ano de 1985 para 2011, demonstrando assim a atuação da atividade econômica no processo de alteração da paisagem, já que as atividades de pastagem e silvicultura sofrem aumento. Em 1985 a vegetação utilizada para pastagem era de 21.6\% e em 2011 estas atinge 43.3\%, já a silvicultura em 1985 não foi classificada como vegetação de cobertura na área do Córrego Dom Tomaz. Em 2011 esta aparece ocupando uma área que soma um total de $21.5 \%$.

Neste sentido podemos concluir apenas através de estudo preliminar em laboratório, análise de imagem de satélite (fotointerpretação), que esta área sofreu, e vem passando por um intenso processo de antropização, já que se somarmos o aumento do pasto e o aparecimento de silvicultura (eucalipto) ocorreram acompanhando os valores das perdas das vegetações naturais (florestal e campestre).

O aparecimento efetivo da classe de silvicultura (eucalipto) é explicado devido á instalação de um grande empreendimento no município de Três Lagoas/MS. A indústria FIBRIA responsável pela produção de celulose, fez com que alguns fazendeiros associassem sua produção de criação de gado para corte a produção da cultura de eucalipto.

Ocorre que esta produção tende a aumentar, já que encontra-se em processo de instalação a industria ELDORADO DO BRASIL, e será responsável também pela 


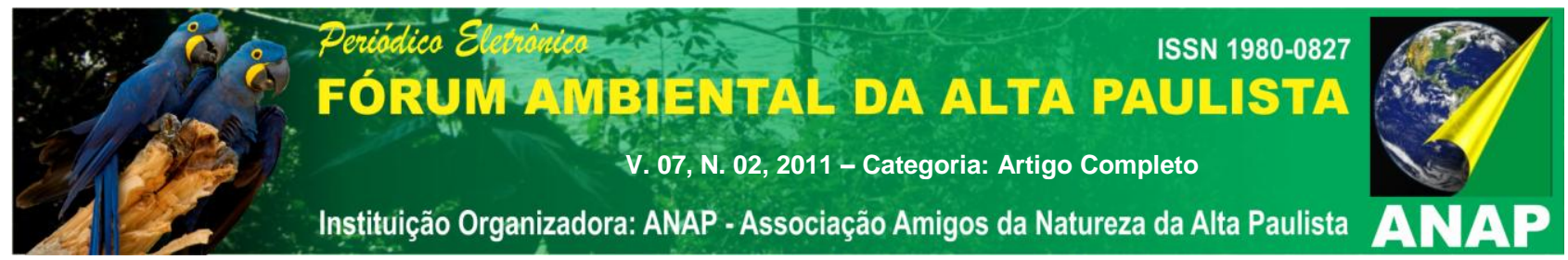

produção de celulose, o que proporcionara mais mudanças no cenário paisagístico do município.

Já as vegetações que compreendem áreas que apresentam alguma umidade devido à proximidade com os corpos d'água (várzeas e foz) e/ou áreas com algum tipo de depressão, não apresentaram valores tão significativos que possam ser associados a estas vegetações reduzidas já que o período de analise da imagem Landsat 5 sensor TM, corresponde ao período de inverno, sendo característicos os índices baixos de precipitações segundo a classificação de Köpen (Aw- inverno frio e seco). Em 1985 correspondia a cerca de aproximadamente 5.3\% e 5.6\% em 2011.

Motivo pelo qual podemos também verificar o baixo índice de densidade, dos canais de drenagem, que atingem 2.8\% em 1985 e passa para 3.4\% em 2011. Juntamente com esta classe podemos verificar que os valores de áreas com solo exposto também apresentou valores baixos sendo em 1985 2.7\% e em 2011 apenas 1.0\%.

Neste caso observa-se que a área tem intensa cobertura vegetal. Esta cobertura propicia ao Córrego Dom Tomaz índices mais baixos de sedimentos carreados para seu leito, pois a vegetação protege o solo contra o efeito direto das precipitações (gotas de chuva), que causaria ao solo maior índice de materiais particulados, e consequentemente maior erosões do tipo laminar, um dos maiores responsáveis pelos altos índices de transporte de sedimentos.

Bertoni \& Lombardi Neto (1990), destaca que as gotas de chuva causam compactação ao solo e reduz rapidamente sua capacidade de infiltração, sendo grande responsável pelo aumento de enxurradas. Quando o solo é atingido pelas gotas de chuva este diminui rapidamente sua velocidade de infiltração, em proporção ao tamanho das gotas de chuva, principalmente em terrenos planos e vai diminuindo à medida que 0 declive do terreno aumenta.

A tabela 01 abaixo apresenta os valores brutos, que foram quantificados a partir da imagem Landsat 5 sensor TM, com uso do SIG Spring® 5.0 .6 em laboratório e a Figura 03 o mapeamento.

Tabela 01: Uso e Cobertura da Terra no Município de Três Lagoas/MS em 1985/2011.

Uso e Cobertura da Terra Área em Quilômetros $\left(\mathrm{Km}^{2}\right)$ Área em Hectares (ha)




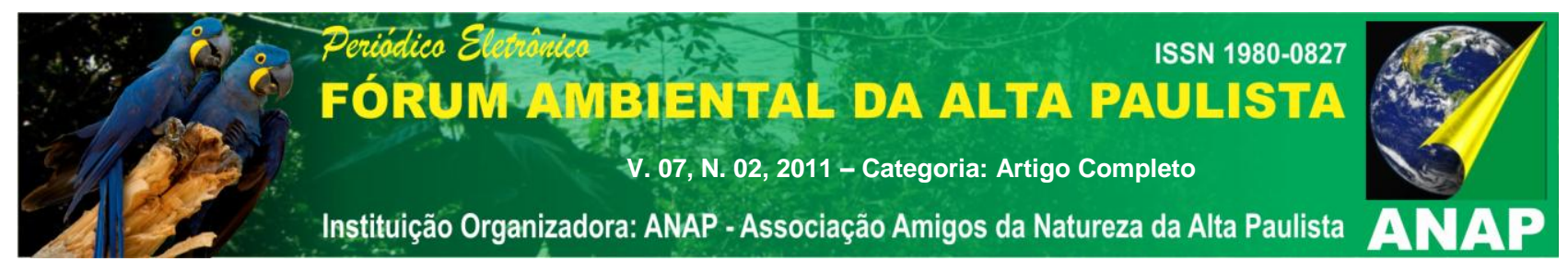

\begin{tabular}{lcccc}
\hline \multicolumn{1}{c}{ Classes } & 1985 & 2011 & 1985 & 2011 \\
Vegetação Natural Florestal & 42.0 & 17.5 & 42 & 175 \\
Vegetação Natural Campestre & 40.8 & 13.5 & 408 & 135 \\
Silvicultura & - & 26.0 & - & 26 \\
Solo Exposto & 3.3 & 1.2 & 33 & 12 \\
Água & 3.5 & 4.2 & 35 & 42 \\
Área Úmida & 6.5 & 7.2 & 65 & 72 \\
Pastagem & 26.5 & 53.0 & 265 & 53 \\
Área Total Aproximada & 122.6 & 122.6 & 1226 & 122.6 \\
\hline
\end{tabular}

Fonte: Processamento digital de imagem de satélite Landsat 5 sensor TM 1985/07/30 e 2011/06/20.

Organização: IZIPPATO, Flávia Joise. 2011 

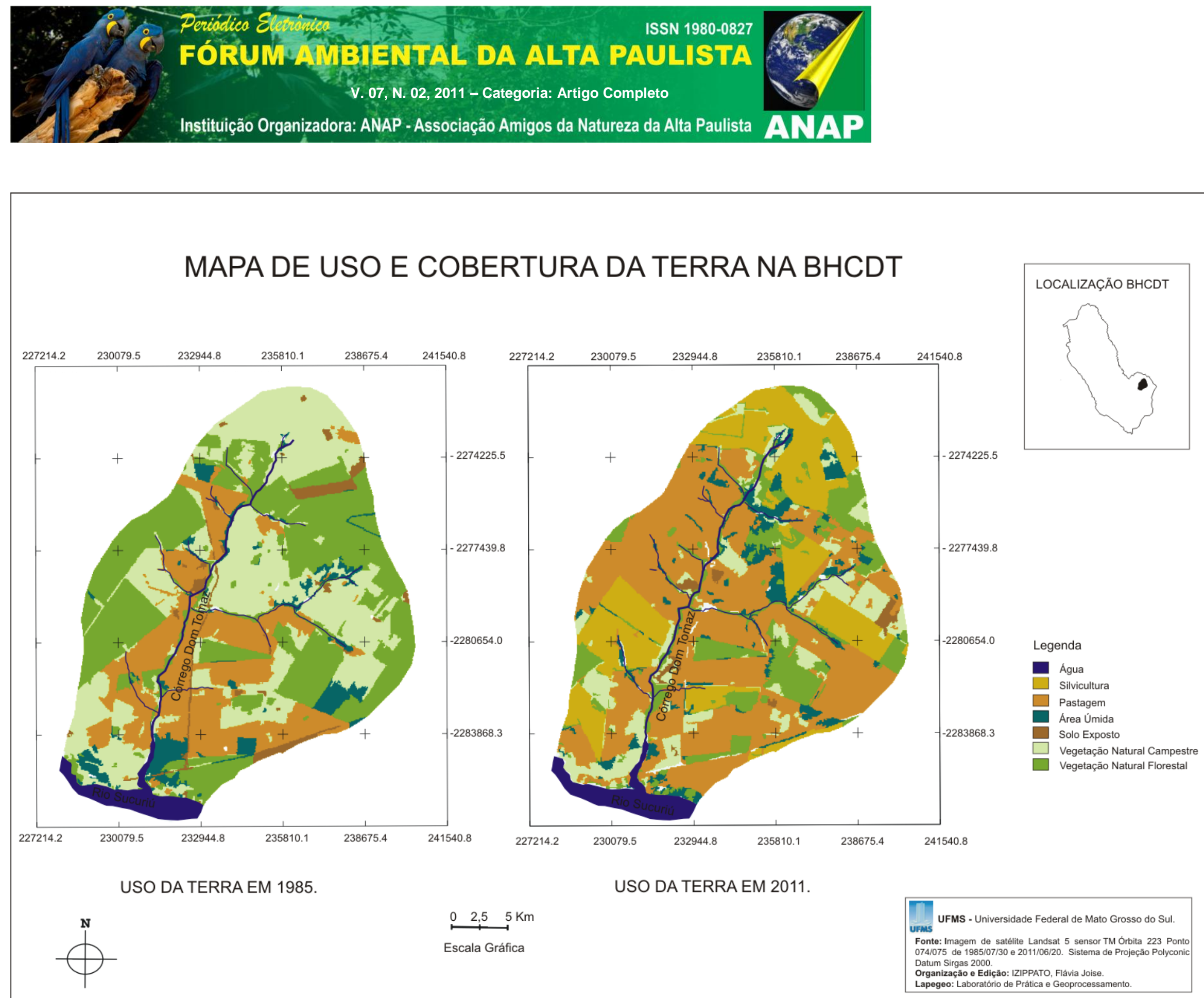


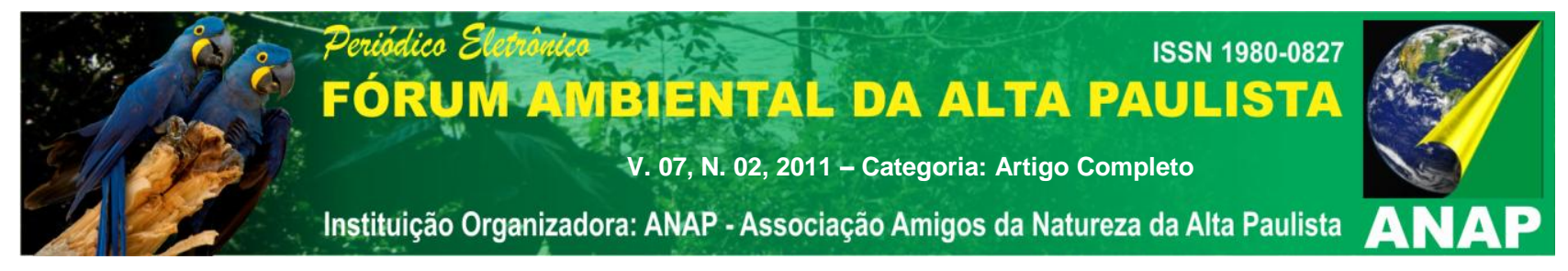

Figura 03: Mapa de Uso e Cobertura da Terra na BHCDT em 1985 e 2011. 


\section{Periódica Elevrandea wh
ISSN 1980-0827

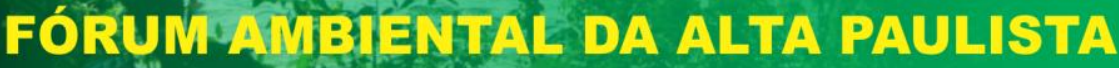 \\ V. 07, N. 02, 2011-Categoria: Artigo Completo}

Instituição Organizadora: ANAP - Associação Amigos da Natureza da Alta Paulista

\section{CONCLUSÃO}

A pesquisa desenvolvida a partir das geotecnologias, mostraram-se satisfatórias, no levantamento dos tipos de uso e cobertura da terra, ao longo dos 26 anos (1985-2011). O software Spring® 5.0.6, possibilitou a análise preliminar (laboratório). Estas ferramentas como foi destacado viabilizou a análise do ambienta de uma forma bem próxima da realidade do campo. Destacando sempre que estes estudos preliminares, não tornam o estudo in loco desnecessário, ao contrario são ferramentas que determinam um estudo de forma mais eficiente e pontual.

Os estudos apontaram através dos alvos analisados na imagem de satélite Landsat 5 sensor TM, o uso intenso da pecuária, com aumento crescente no decorrer dos anos, da vegetação utilizada para pasto e também silvicultura. A região do município de Tres Lagoas/MS, está dedicando parte de seu território (sul do município principalmente), para o plantio de silvicultura (eucalipto), para atender a necessidade de produção da empresa Fibria. Em contra partida a vegetação florestal natural e a vegetação natural campestre tem suas áreas reduzidas na mesma proporção em que estas duas classes aumentam sua área de cobertura.

Portanto a análise comprovou que ocorre um processo de antropização do território, onde é possível verificar alterações ambientais, principalmente nas áreas do entorno da BHCDT. Nestes locais a vegetação foi totalmente substituída por atividades atreladas à economia. Vale ressaltar sempre que, as áreas quando bem manejadas proporcionam ao agricultor maiores rendimentos, mas devido à falta de planejamento que se observam na maioria das vezes, o resultado observado quase sempre é um aumento de áreas potencialmente degradadas.

O problema não é o uso da terra para atividades econômicas como exemplo a pastagem, o problema é a falta de técnicas preventivas quanto ao seu uso como destaca Bertoni e Lombardi Neto (1990) que a depauperação das terras esta associado quase sempre ao seu uso intensificado e por tempo indeterminado, principalmente para produção de gado, atrelado a falta de manejo.

\section{REFERÊNCIAS BIBLIOGRÁFICAS}




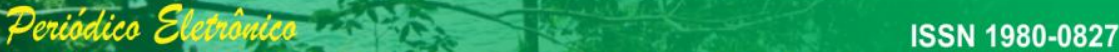

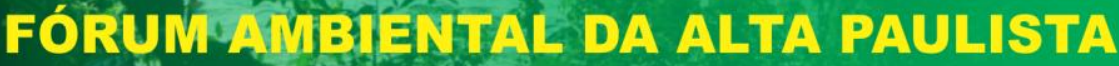 \\ V. 07, N. 02, 2011 - Categoria: Artigo Completo}

Instituição Organizadora: ANAP - Associação Amigos da Natureza da Alta Paulista

ARAUJO, G. H. S; ALMEIDA, J. R \& GUERRA, A. J. Gestão Ambiental de Áreas

Degradadas. Rio de janeiro: Bertrand Brasil, 2008.320 p.

BERTONI, J \& LOMBARDI NETO, F. Conservação do Solo. São Paulo: Ícone, $1990.355 p$

CÂMARA, G.; DAVIS, C. Capítulo 1: Apresentação. In: CÂMARA, G; DAVIS, C. e MONTEIRO, A. M. V. Introdução à Ciência da Geoinformação. Disponível em: <http://www.dpi.inpe.br/gilberto/livro/introd/>. Acesso em: 12 de maio de 2008.

CÂMARA, G.; SOUZA, R. D. M.; FREITAS, U. M.; GARRIDO, J. \& MITSUO, F. Spring: integrating Remote Sensing and GIS by object - Oriented Data Modelling. São Jose dos Campos, 1996, 17p. Disponível em: http://citeseerx.ist.psu.edu/viewdoc/download?doi=10.1.21.3610\&rep=rep1\&tyte=pdf. cesso em 12/05/2011.

DAVIS \& CÂMARA, G. Arquitetura de Sistemas de Informação Geográfica. In CÂMARA, G.; DAVIS, C. \& MONTEIRO, A. M. V. (Org.). Introdução a Ciência da Geoinformação. São Jose dos Campos, 2001 345p. Disponível em: www.geolab.faed.udesc.br/paginaweb/...files/introducao.pdf. Acesso em 30/03/2010.

FITZ, Paulo Roberto. Geoprocessamento sem complicação. São Paulo: Oficina de Textos, 2008. 160p.

FLORENZANO, Tereza Gallotti (org.). Geomorfologia: conceitos e tecnologias atuais. São Paulo: Oficina de Textos, 2008. 318p.

IBGE. Manual Técnico do Uso da Terra. Ed. 2, n. 7. Rio de Janeiro, 2006

IZIPPATO, Flávia Joise. Avaliação das Alterações Ambientais na Bacia do Ribeirão do Meio - Brasilândia/MS. 2010, Monografia (Graduação em Geografia) - Universidade Federal de Mato Grosso do Sul, Três Lagoas.

LANDSAT-5. Disponível em: http:/dgi.inpe.br/catalogo/ Acesso em: 15 Ago. 2011.

LEPSCH, I. F. Formação e Conservação do Solo. São Paulo: Oficina de Textos, 2002. $177 p$.

MIRANDA, E. E. de; (Coord.) Brasil em Relevo. Campinas: Embrapa Monitoramento por Satélite, 2005. Disponível em:<HTTP://relevobr.cnpm.embrapa.br. Acesso em: 24 de junho de 2011. 


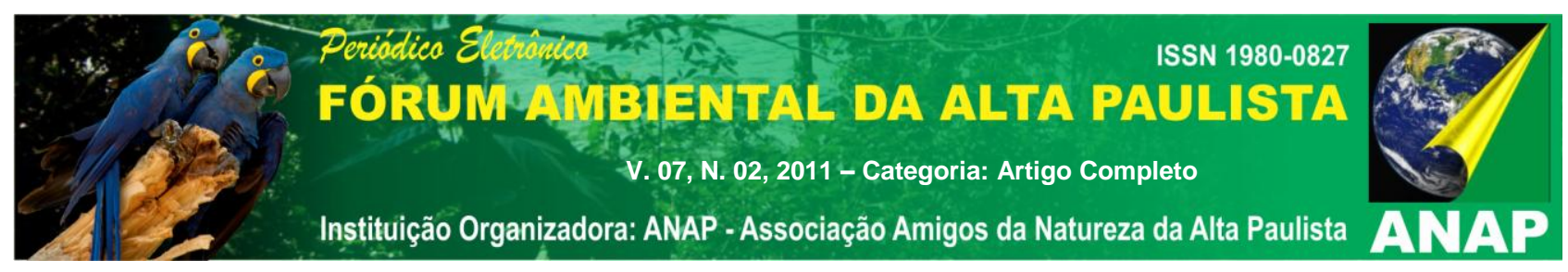

MIRANDOLA - AVELINO, Patricia. Helena. Análise Geo - Ambiental Multitemporal para fins de Planejamento Ambiental: Um exemplo aplicado à Bacia Hidrográfica do Rio Cabaçal Mato Grosso - Brasil. Tese de Doutorado em Geografia do Programa de Pós Graduação em Geografia da Universidade Federal do Rio de Janeiro, 2006. 317 p.

NOVO, Evlyn M. L. de Moraes. Sensoriamento Remoto: princípios e aplicações. São Paulo, Editora Edgard Blücher Ltda, 1989.

PARANHOS FILHO, Antonio Conceição; LASTORIA, Giancarlo \& TORRES, Thais Gisele. Sensoriamento Remoto Ambiental Aplicado: introdução às geotecnologias. Campo Grande, MS: Ed. UFMS, 2008. 198p.

SEPLAN, Atlas Multirreferencial. Secretaria de Planejamento e Coordenação Geral, Fundação IBGE, 1990.

SPRING - Sistema de Processamento de Informações Georreferenciadas. Disponível em: http://www.dgi.inpe.br/spring/. Acesso em: 10 Março de 2011.

TRICART, Jean. Ecodinâmica. Rio de Janeiro, IBGE, Diretoria Técnica, SUPREN, 1977. $91 p$. 